\title{
Self-Marketing Strategies of Elite Sportmen through the Media
}

\author{
Bulent Duran \\ Coaching Training Department, Istanbul University-Cerrahpasa, Istanbul, Turkey \\ E-mail: bulentduran@ hotmail.com \\ Cemal Guler (Corresponding author) \\ Department of Sports Management, Istanbul University-Cerrahpasa, Istanbul, Turkey \\ E-mail: cemal.guler95@gmail.com \\ Ataman Tukenmez \\ Department of Sports Management, Istanbul University-Cerrahpasa, Istanbul, Turkey \\ E-mail: atamantukenmez@gmail.com
}

\begin{abstract}
Social media became such a way where people could share easily about themselves, like continuously refreshing network and enabling multiple communication. At the same time people sharing instant photos and videos led to real life transforming to virtual. That transformation exposed at sport sector so as especially professional sportmen begin to address their fans and communicate with social media. In this context our study aimed to examine how strategies elite sportmen from different branches follow while self-marketing on social media. Two popular and also active twitter users sportmen from each football, basketball, tennis, american football, baseball and golf branches participated to the study. In our study content analysis method from qualitative research methodologies used for examining twitter accounts. Tweets of sportmen from the years 2019 and 2018 examined with references of Pegoraro's (2010) study which are "relating to personal life, relating to business life, relating to their sport, other sport or athlete reference, responding to fans, pop culture or landmark reference". According to the results of 12 months research showed that Ronaldo raised his follows and became first with 8M, though Ian Paulter lost $100 \mathrm{~K}$ follows during this time. While tweet champs were footballers with 110 tweets in 2018, in 2019 the basketballers took top with 117 tweets. Comparison of 2019 vs 2018 twitterers concluded that Lebron James is the champ of both.
\end{abstract}

Keywords: elite sportmen, self marketing, social media.

DOI: $10.7176 / \mathrm{JSTR} / 7-01-02$

\section{Elit Sporcuların Sosyal Medya Aracılığıyla Kendini Pazarlama Stratejileri}

\section{Özet}

Günümüzde sosyal medya insanların fikirlerini kolaylıkla paylaşabildiği, kendini sürekli yenileyen ve çoklu iletişime olanak sağlayan bir ağ haline gelmiştir. Aynı zamanda bireyler fotoğraflar ve videolar paylaşarak gerçek dünyanın sanal ortama dönüşümü sağlanmıştır. Yaşanan bu dönüşüm spor sektöründe de kendini göstermeye başlamış, özellikle profesyonel sporcuların sosyal medya platformlarında hayran kitlesine hitap etme ve iletişim kurma ihtiyacını ortaya çıkarmıştır. Bu bağlamda çalışmanın amacı, farklı branşlarda yer alan elit sporcuların sosyal medya aracılığıyla kendini pazarlama (self-marketing) stratejilerinin incelenmesidir. Futbol, basketbol, tenis, amerikan futbolu, beyzbol ve golf branşlarını incelediğimiz çalışmada, twitter platformunu aktif olarak kullanan

17 | P a g e

www.iiste.org 
ve popüler olan ikişer sporcu çalışmaya dahil edilmiştir. Çalışmamızda twitter hesapları incelenirken nitel araştırma yöntemlerinden içerik analizi tekniği kullanılmıştır. Çalışma kapsamında sporcuların 2018 ve 2019 tarihlerinde paylaştığı tweetler Pegoraro'nun (2010) yapmış olduğu çalışmada belirlediği "relating to personal life, relating to business life, relating to their sport, other spor tor athlete reference, responding to fans, pop culture or landmark reference" alt boyutlar dikkate alınarak incelenmiştir. Araştırma sonucuna göre, 12 aylık araştırma süre boyunca takipçi sayısını arttıran sporcu 8 milyon ile Ronaldo olurken, Ian Paulter ise bu sürede 100 bin takipçi kaybetmiştir. 2018 yılında 110 tweet ile en çok futbol branşında yer alan sporcular tweet atarken, 2019 y1lında zirveye 117 tweet ile basketbol sporcuları çıkmıştır. 2018 ve 2019 yılları karşılaştırıldığında en çok tweet ise Lebron James tarafindan atıldığı sonucuna ulaşılmıştır.

Anahtar kelimeler: Elit sporcu, kendini pazarlama, sosyal medya.

\section{Giriş}

World Wide Web teknolojisinin 1990'ların başında gelişmesi, medyada bir değişim ve büyüme patlamasına yol açtı ve küreselleşme süreci ile birlikte sporun kapsamını kişilerarası, kültürlerarası ve uluslararası bir kamu malı haline getirdi. Daha önce yazılı basında gecikmeye maruz kalan iletişim teknolojileri, artık, düzinelerce format aracılı̆̆ıla anında erişilebilir durumda (Lee, 2015). Teknolojideki bu gelişmeler, spor tutkunlarının en sevdikleri sporcuları, takımları ve sporları istedikleri zaman takip etmelerini ve hayran deneyimini genişletme ve zenginleştirme yollarını mümkün kılmıştır (Gantz ve Lewis, 2014).

Sosyal medya, sürekli güncellenebilmesi, çoklu kullanıma açık olması, sanal paylaşıma olanak tanıması vb. açısından en ideal mecralardan biri olarak kendini göstermektedir. İnsanlar sosyal medyada günlük düşüncelerini yazmakta, bu düşünceler üzerine tartş̧abilmekte ve yeni fikirler ortaya koyabilmektedirler. Ayrıca kişisel bilgilerinin yanında çeşitli fotoğraflar, videolar, paylaşabilmekte, iş arayabilmekte ve hatta bulabilmekte ayrıca sıkılmadan gerçek dünyayı sanal ortamda yaşayabilmektedirler. Bu durum gün geçtikçe tüm dikkatlerin bu alana yönelmesine sebep olmakta ve yenilenen sanal dünyaya yeni bir kavramsal çerçeve çizmektedir (Vural ve Bat, 2010). Markalar, bir pazarlama iletişimi kampanyasında entegre bir iletişim bileşeni olarak devam eden bir kurumsal iletişim kanalı olarak ve/veya dijital maruziyet için özel olarak tasarlanmış bir dizi mikro-kampanya olarak sosyal medya pazarlamasını kullanabilir (Ashley ve Tuten, 2015). Değişsen yeni dünyaya markaların ayak uydurduğunu ve pazarlama faaliyetlerini sosyal medya üzerinden yapmaları, kişisel birer marka olan sporcuları da harekete geçirmiştir. Özellikle dünya çapında üne sahip olan sporcular da sosyal medyanın gücünü fark edip, kişisel sayfalarını birer kişsisel markalama aracı olarak kullanmaya başlamışlardır. Shepherd (2005), kişisel markalama terimini kişinin kendisini pazarlaması (self marketing) olarak ifade etmekte, kişinin kendisiyle ilgili pazarlama faaliyetlerinin amacının kişinin pazarda bilinir olmasını sağlayarak, kazançlı bir istihdam sağlamak olduğunu da belirtmiştir.

Markaların cazip kitle segmentleri ile iletişim kurması için çevrimiçi kanalları içeren sosyal medya, giderek daha önemli bir yolu temsil etmektedir (Murdough, 2009). Son yıllarda spor ve sosyal medya üzerine yapılan çok sayıdaki araştırma, sporcuların bu platformlarda kültürel ve sosyal konuların yoğun olarak paylaşıldığı ve sporcu taraftar bağını geliştirdiği görülmüştür. Aynı zamanda yapılan çalışmalarda en fazla ilgi gören platformlar, bloglar, Twitter, Facebook ve Instagram olmuştur (Frederich, 2017). Pagoraro (2010), bu sosyal platformlar arasında, en çok dikkati çekenin ise Twitter olduğunu vurgulamıştır. Sosyal medyanın halkla ilişkiler uzmanları ve kitle iletişim araçları ile yönlendirilen geleneksel medya uygulamalarından farklı olması, özünde kişinin kendini tanıtması için devamlı yenilenen, dinamik yapıda olmasıdır (Lebel ve Danylchuk, 2012). Sporcular bu platformları hayranlarıyla etkileşim kurmak, marka oluşturmak ve yönetmek, negatif medya portrelerine karș1 koymak için kullanırken, diğer taraftan sporculara yönelik hakaret içeren içerikler gönderme firsatı da sunuyor (Frederich, 2017). Diğer yandan sporcular ve kulüpler paylaştıkları bir gönderi sonrası ceza alabilmektedir. 15 Kasım 2013'de kendi twitter hesabı üzerinden başka bir oyuncuya yönelik düşmanca ve uygunsuz bir dil kullandığı için J.R. Smith 25.000 \$ ceza aldı. Aynı şekilde birçok ülkeden birçok oyuncu, yönetici vd. sosyal medya paylaşımları sebebiyle ceza alıyor (Pagoraro, 2010).

Türkiye Futbol Ligi'nde yer alan Altınordu Kulübü, 27.08.2018 tarihinde ligin iddiasız Kardemir Karabükspor maçı öncesinde, twitter hesabından, "Sezonunu ilk galibiyetini izlemek için saat 19.15 ten sonra kimselere randevu vermeyin, bekliyoruz." paylaşımda bulunmuştu. Daha sonra kulüp yetkilileri yaptıkları hatanın farkına varıp, kendilerine sosyal medyadan 1 aylık ihraç etme cezası vermişlerdir. (http://www.milliyet.com.tr/altinordu-baskani-ozkan-dan-sosyal---2732128-skorerhaber) (Erişim tarihi:

18 | P a g e

www.iiste.org 
05.01.2020). 22 Şubat 2018 tarihinde Türkiye Futbol Ligi takımlarından Galatasaray, bir karşılaşma sonrası maçın hakemini ima eden bir tweet atınca, 100.000 TL ceza almaktan kurtulamadı. (https://www.gzt.com/spor/galatasaraya-sosyal-medya-cezasi-100-bin-tl-3147959) (Erişim tarihi: 05.01.2020) Ayrıca karşılaşma sonrasında sporcularla iletişime geçmek için de sosyal medya biçilmiş kaftan. Öyle ki bazen taraftarlar sınırlarının ötesine geçebiliyor ve sporcuların karşılaşma esnasında yaptıkları hatalar sebebiyle onlara, sosyal medya aracılığıyla, irkçı ya da tehditkar söylemlerde bulunabiliyorlar. Özellikle Ağustos 2019'da Manchester United'ın menajeri Ole Gunnar Solskjaer, yıldız oyuncularının kaçırdıkları penaltı sonrası sosyal medya üzerinden aldıkları ırkçı mesajlara tepki göstermiştir. İngiltere Kadın Milli Takımı'nın menajeri Phil Neville ise, bu durumu çözmek için futbol topluluklarına altı ay süreyle sosyal medya hesaplarını kapatma teklifinde bulundu. (BBC, 2020).

\section{Gereç ve Yöntem}

Bu çalışmada sporcuların Twitter sosyal medya hesaplarını nasıl birer kişisel pazarlama aracı olarak kullandıklarını ölçmek için Ağustos 2018 ve Ağustos 2019 içerisindeki paylaşımları dikkate alınmıştır. Çalışmamızda twitter hesaplarını incelerken nitel araştırma yöntemlerinden içerik analizi tekniği kullanılmıştır. Araştırma için sporcular futbol, basketbol, tenis, amerikan futbolu, beyzbol ve golf branşlarından seçilmiştir. Seçilen sporcular branşlarında elit sporcu düzeyinde olup, birçoğu twitter hesabını aktif olarak kullanmaktadır. Bu araştırma sonucunda cevaplanmak istenilen sorular aşağıda verilmiştir:

\section{S1: Sporcular sosyal medya hesaplarını birer kişisel pazarlama aracı olarak kullanıyorlar mı?}

S2: Sporcular sosyal medya hesaplarında uyguladıkları pazarlama faaliyetlerindeki stratejilerini nasıl oluşturuyorlar?

S3: Sporcuların kendi branşındaki diğer sporcularla uyguladıkları kişisel pazarlama faaliyetleri arasında farklilık var mi?

S4: Sporcuların branşları ya da yer aldıkları kıta kişisel pazarlama stratejilerini etkiliyor mu?

Çalışmamıza dahil olacak sporcular belirlenirken, öncelikle dünya üzerinde popüler olan spor branşları dikkate alınmıştır. Daha sonra sporcuların, bu branşlarda üne sahip olmasının ve twitter hesaplarını aktif kullanmasının çalışmayı daha önemli kılacağı düşünülmüştür. Daha sonra çalışmaya katılan sporcuların (n=12) Ağustos 2018 ve Ağustos 2019 dönemlerinde attığı 437 tweet incelenmiştir.

Çalışmada sporcuların Twitter hesapları incelenirken, Pegoraro'nun (2010) yaptığ önceki çalışmada belirlediği alt boyutlar dikkate alınmıştır. Bu alt boyutları sıralamak gerekirse; relating to personal life, relating to business life, relating to their sport, other spor tor athlete reference, responding to fans, pop culture or landmark reference.

\section{Bulgular}

Araştırmamızın bu kısmında örneklem grubuna aldığımız sporcuların branşları twitter adresleri toplam takipçi sayıları ve attıkları tweetler ele alınmıştır. Yaptığımız çalışma dönemlerinde sporcuların ne kadar tweet attıkları ayrıca belirtilmiştir. Daha sonra sporcuların hangi alt boyutlarda kaç tane tweet attıkları gösterilmiştir. Son kısımda ise sporcuların branşlara göre tweet atma sıklıkları yüzdelik olarak ifade edilmiş ve tablo haline getirilmiştir. 
Tablo 1. Sporcuların, Twitter hesap, takipçi ve Ağustos ayı tweet sayıları (Ağustos, 2018)

\begin{tabular}{|c|c|c|c|c|c|}
\hline SPORCU & BRANŞI & ADRESİ & $\begin{array}{l}\text { TOPLAM } \\
\text { TAKİPÇI }\end{array}$ & $\begin{array}{l}\text { TOPLAM } \\
\text { TWEET }\end{array}$ & \begin{tabular}{|c|} 
Ăgustos \\
2018
\end{tabular} \\
\hline Cristiano Ronaldo & Futbol & $@$ Cristiano & 74,6 milyon & 3,264 bin & 21 \\
\hline Neymar & Futbol & @ neymarjr & 41 milyon & 41,2 bin & 29 \\
\hline Lebron James & Basketbol & @ KingJames & 41,5 milyon & 5,938 bin & 39 \\
\hline Stephen Curry & Basketbol & @ StephenCurry30 & 12,8 milyon & 6,946 bin & 15 \\
\hline Roger Federer & Tenis & @ rogerfederer & 12,3 milyon & 1,654 bin & 5 \\
\hline Rafael Nadal & Tenis & $@$ RafaelNadal & 15,6 milyon & 2,718 bin & 10 \\
\hline Drew Brees & Amerikan Futbolu & @drewbrees & 3,1 milyon & 3,709 bin & 20 \\
\hline Aaron Rodgers & Amerikan Futbolu & @ AaronRodgers12 & 4,42 milyon & 2,960 bin & 13 \\
\hline DeMarcus Lawrance & Beyzbol & @TankLawrance & $126 \mathrm{bin}$ & 306 & 9 \\
\hline Cole Beasley & Beyzbol & $@$ Bease11 & 433 bin & 6,881 bin & 26 \\
\hline Tiger Woods & Golf & @TigerWoods & 6,31 milyon & 863 & 24 \\
\hline İan Paulter & Golf & @IanJamesPoulter & 2,31 milyon & 22,7 bin & 17 \\
\hline
\end{tabular}

Cristiano Ronaldo 1-31 Ağustos 2018 tarihleri arasında 74,6 milyon takipçisi olan Cristiano hesabından toplamda 21 tweet atmıştır.

Neymar 1-31 Ağustos 2018 tarihleri arasında 41 milyon takipçisi olan neymarjr hesabından toplamda 29 tweet atmıştır.

Lebron James 1-31 Ağustos tarihleri arasında 41,5 milyon takipçisi olan KingJames hesabından toplamda 39 tweet atmıştır.

Stephen Curry 1-31 Ağustos 2018 tarihleri arasında 12,8 milyon takipçisi olan StephenCurry30 hesabından toplamda 15 tweet atmıştır.

Roger Federer 1-31 Ağustos 2018 tarihleri arasında 12,3 milyon takipçisi olan rogerfederer hesabından toplamda 5 tweet atmıştır.

Rafa Nadal 1-31 Ağustos 2018 tarihleri arasında 15,6 milyon takipçisi olan RafaelNadal hesabından toplamda 10 tweet atmıştır.

Drew Brees 1-31 Ağustos 2018 tarihleri arasında 3,1 milyon takipçisi olan drewbrees hesabından toplamda 20 tweet atmiştır.

Aaron Rodgers 1-31 Ağustos 2018 tarihleri arasında 4,42 milyon takipçisi olan AaronRodgers12 hesabından toplamda 13 tweet atmıştır.

DeMarcus Lawrance 1-31 Ağustos 2018 tarihleri arasında 126 bin takipçisi olan TankLawrance hesabından toplamda 26 tweet atmıştır.

Cole Beasley 1-31 Ağustos 2018 tarihleri arasında 433 bin takipçisi olan Bease11 hesabından toplamda 21 tweet atmıştır.

Tiger Woods 1-31 Ağustos 2018 tarihleri arasında 6,31 milyon takipçisi olan TigerWoods hesabından toplamda 24 tweet atmıştır.

İan Paulter 1-31 Ağustos 2018 tarihleri arasında 2,31 milyon takipçisi olan IanJamesPaulter hesabından toplamda 17 tweet atmıştır. 
Tablo 2. Sporcuların Alt boyutlara göre tweet atma sayıları (Ağustos, 2018)

\begin{tabular}{|c|c|c|c|c|c|c|c|}
\hline Sporcu & $\begin{array}{c}\text { Kişisel } \\
\text { Hayatı }\end{array}$ & $\begin{array}{c}\text { Iş } \\
\text { Hayatı }\end{array}$ & $\begin{array}{c}\text { Kendi } \\
\text { Branşı }\end{array}$ & $\begin{array}{c}\text { Diğer } \\
\text { Branşlar }\end{array}$ & $\begin{array}{c}\text { Taraftarlara } \\
\text { Cevap }\end{array}$ & $\begin{array}{c}\text { Popüler } \\
\text { Kültür }\end{array}$ & $\begin{array}{c}\text { Resim + } \\
\text { Video }\end{array}$ \\
\hline $\begin{array}{c}\text { Cristiano } \\
\text { Ronaldo }\end{array}$ & 11 & 9 & 9 & 0 & 0 & 0 & 17 \\
\hline Neymar & 13 & 8 & 11 & 0 & 1 & 4 & 27 \\
\hline $\begin{array}{c}\text { Lebron } \\
\text { James }\end{array}$ & 22 & 1 & 5 & 2 & 4 & 8 & 32 \\
\hline $\begin{array}{c}\text { Stephen } \\
\text { Curry }\end{array}$ & 9 & 1 & 5 & 1 & 0 & 0 & 14 \\
\hline $\begin{array}{c}\text { Roger } \\
\text { Federer }\end{array}$ & 1 & 0 & 3 & 0 & 1 & 0 & 3 \\
\hline $\begin{array}{c}\text { Rafael } \\
\text { Nadal }\end{array}$ & 2 & 1 & 4 & 0 & 3 & 1 & 6 \\
\hline Drew Brees & 8 & 1 & 7 & 2 & 1 & 3 & 10 \\
\hline $\begin{array}{c}\text { Aaron } \\
\text { Rodgers }\end{array}$ & 6 & 3 & 4 & 2 & 1 & 1 & 8 \\
\hline $\begin{array}{c}\text { DeMarcus } \\
\text { Lawrance }\end{array}$ & 2 & 4 & 6 & 0 & 0 & 0 & 9 \\
\hline $\begin{array}{c}\text { Cole } \\
\text { Beasley }\end{array}$ & 10 & 2 & 4 & 3 & 3 & 1 & 14 \\
\hline $\begin{array}{c}\text { Tiger } \\
\text { Woods }\end{array}$ & 2 & 19 & 21 & 0 & 1 & 0 & 22 \\
\hline Ian Paulter & 3 & 8 & 13 & 1 & 1 & 1 & 13 \\
\hline
\end{tabular}

Cristiano Ronaldo 21 tweetinin 11'ini kişisel hayatıyla ilgili, 9'unu iş hayatıyla ilgili, 9'unu kendi branşıyla ilgili, 17'sini resim/video olarak twitlemiştir.

Neymar 29 tweetinin 13'ünü kişisel hayatıyla ilgili, 8'ini iş hayatıyla ilgili, 11'ini kendi branşıyla ilgili,1'ini Taraftarlara Cevap olarak, 4'ünü Popüler Kültürle ilgili, 27'sini resim/video olarak twitlemiştir.

Lebron James 39 tweetinin 22'sini kişisel hayatıyla ilgili, 1'ini iş hayatıyla ilgili, 5'ini kendi branşıyla ilgili, 2'sini Diğer Branşlarıyla ilgili, 4'ini Taraftarlara Cevap olarak, 8'ünü Popüler Kültürle ilgili, 32'sini resim/video olarak twitlemiştir.

Stephen Curry 15 tweetinin 9'sini kişisel hayatıyla ilgili, 1'ini iş hayatıyla ilgili, 5'ini kendi branşıyla ilgili, 1'sini Diğer Branşlarıyla ilgili, 14'sini resim/video olarak twitlemiştir.

Roger Federer 5 tweetinin 1'sini kişisel hayatıyla ilgili, 3'ini kendi branşıyla ilgili, 1'ini Taraftarlara Cevap olarak, 3'sini resim/video olarak twitlemiştir.

Rafael Nadal 10 tweetinin 2'sini kişisel hayatıyla ilgili, 1'ini iş hayatıyla ilgili, 4'ini kendi branşıyla ilgili, 3'ini Taraftarlara Cevap olarak, 1'ünü Popüler Kültürle ilgili, 6'sini resim/video olarak twitlemiştir.

Drew Brees 20 tweetinin 8'sini kişisel hayatıyla ilgili, 1'ini iş hayatıyla ilgili, 7'ini kendi branşıyla ilgili, 2'sini Diğer Branşlarıyla ilgili, 1'ini Taraftarlara Cevap olarak, 3’ünü Popüler Kültürle ilgili, 10'sini resim/video olarak twitlemiştir.

Aaron Rodgers 13 tweetinin 6'sini kişisel hayatıyla ilgili, 3'ini iş hayatıyla ilgili, 4'ini kendi branşıyla ilgili, 2'sini Diğer Branşlarıyla ilgili, 1'ini Taraftarlara Cevap olarak, 1'ünü Popüler Kültürle ilgili, 8'sini resim/video olarak twitlemiştir.

DeMarcus Lawrance 26 tweetinin 2'sini kişisel hayatıyla ilgili, 4'ini iş hayatıyla ilgili, 6'ini kendi branşıyla ilgili, 9'sini resim/video olarak twitlemiştir. 
Cole Beasley 21 tweetinin 10'sini kişisel hayatıyla ilgili, 2'ini iş hayatıyla ilgili, 4'ini kendi branşıyla ilgili, 3'sini Diğer Branşlarıyla ilgili, 3'ini Taraftarlara Cevap olarak, 1'ünü Popüler Kültürle ilgili, 14'sini resim/video olarak twitlemiştir.

Tiger Woods 24 tweetinin 2'sini kişisel hayatıyla ilgili, 19'ini iş hayatıyla ilgili, 21'ini kendi branşıyla ilgili, 1'ini Taraftarlara Cevap olarak, 22'sini resim/video olarak twitlemiştir.

Ian Paulter 17 tweetinin 3'sini kişisel hayatıyla ilgili, 8'ini iş hayatıyla ilgili, 13'ini kendi branşıyla ilgili, 1'sini Diğer Branşlarıyla ilgili, 1'ini Taraftarlara Cevap olarak, 1'ünü Popüler Kültürle ilgili, 13 'sini resim/video olarak twitlemiştir.

Tablo 3. Sporcuların branşlara göre tweetlerinin yüzdelik dağılımı (Ağustos, 2018)

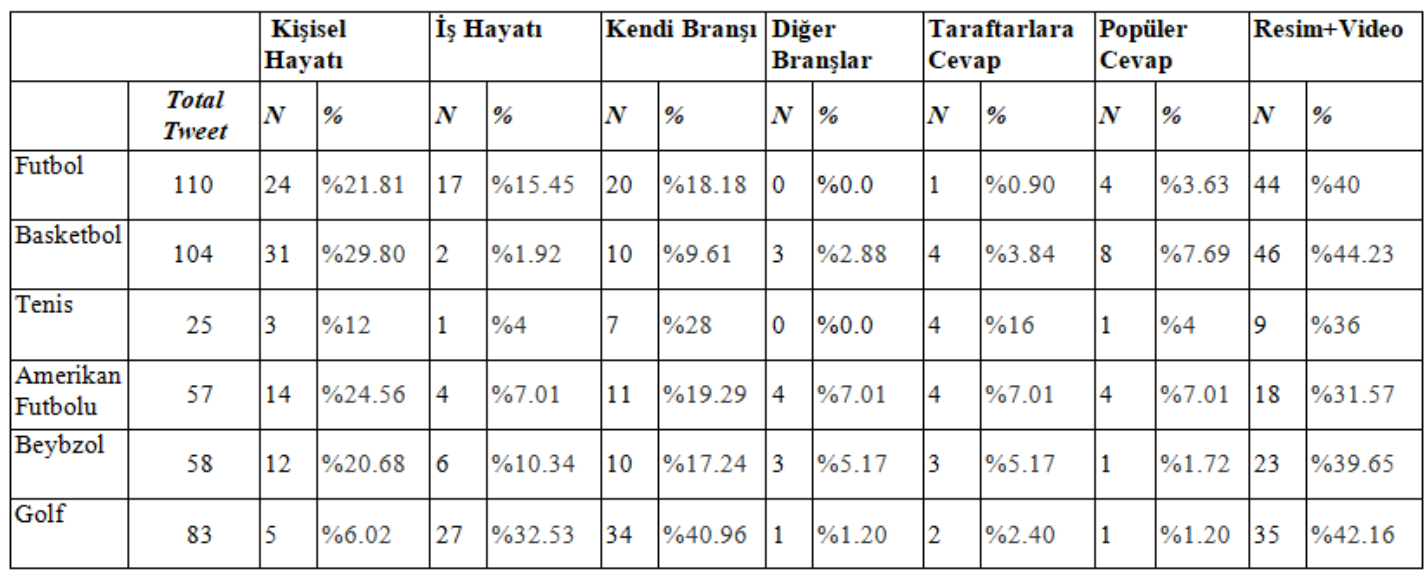

Araştırmamızda veri toplamayı kolaylaştırmak için branşa göre twitter kullanan iki sporcu seçildi.

Bu çalışmada Futbol (2 sporcu), Basketbol (2 sporcu), Tenis (2 sporcu), Amerikan Futbolu (2 sporcu), Beyzbol (2 sporcu) ve Golf (2 sporcu) branşlarından toplam 12 sporcu ve 437 mesaj üzerinden incelendi. İlk veri sonuçlarından itibaren, Futbol ve Basketbol branşıyla uğraşan sporcuların Twitter kullanım sıklığı diğer branşlara göre daha fazla olduğunu görmekteyiz.

Basketbol branşıyla uğraşan sporcuların Kişisel hayatı ile ilgili atmış olduğu tweet oranı \%29,80 ile zirvede yer alırken, Golf oyuncularında bu tweet sayısı \%6,02 ile sonuncu sirada kendine yer bulmuştur. Ancak İş Hayatı ile ilgili atılan tweet oranlarına baktığımızda Golf branşıyla ilgilenen sporcular \%32,53 ile diğer branşlara göre ilk sırada yer alırken, Basketbol branşında bu oran \%1'dir. Sporcuların Kendi Branşı kategorisinde atmış oldukları tweet sayısında yine Golf sporcuları \% 40,96 ile birinci sırada yer almaktadır. Aynı kategorideki tweet sayısına göre Basketbol sporcuları \%9,61 ile son siradadir.

Diğer branşlarla ilgili atılan tweet sayısında tüm sporcuların oranlarına baktığımızda yüksek bir sayı çıkmamaktadır. \%5,17 ile Beyzbol ilk sırada yer alırken, Futbol ve Basketbol branşlarında yer alan sporcular ise hiç tweet atmamıştır.

Taraftarlara Cevap kategorisinde atılan tweetlerde Golf sporcuları \%16 ile ilk sirada yer alırken, Futbol branşıyla ilgilenen sporcular \%0,90 oranıyla son sırada yer almaktadır.

Popüler cevaplara bakıldığında tüm branşlarda yer alan sporcuların oranları birbirine yakındır. Ancak \%7,1 ile Amerikan futbolcu branşıly ilgilenen sporcular birinci sırada, \%1,20 ile Golf oyuncuları son sirada yer almaktadir.

Resim + Video paylaşımları yapan sporcuların oranları yüksek çıkmaktadır. Sırasıyla \%44,23 ve \%42,16 ile Basketbol ve Golf sporuyla uğraşan sporcular ilk sırada yer almaktadır. \%31,57 ile Amerikan Futbolu bu kategoride son sirada yer almaktadır. 
Tablo 4. Sporcuların, Twitter hesap, takipçi ve Ağustos ayı tweet sayıları (Ağustos, 2019).

\begin{tabular}{|c|c|c|c|c|c|}
\hline Sporcu & Branşı & Adresi & Toplam Takipçi & $\begin{array}{c}\text { Toplam } \\
\text { Tweet }\end{array}$ & $\begin{array}{c}\text { Ağustos } \\
\mathbf{2 0 1 9}\end{array}$ \\
\hline $\begin{array}{c}\text { Cristiano } \\
\text { Ronaldo }\end{array}$ & Futbol & @ Cristiano & 82,6 milyon & 3,506 bin & 11 \\
\hline Neymar & Futbol & @ neymarjr & 45,5 milyon & 41,6 bin & 7 \\
\hline Lebron James & Basketbol & @ KingJames & 45 milyon & 6,854 bin & 59 \\
\hline Stephen Curry & Basketbol & @StephenCurry30 & 14 milyon & 7,189 bin & 7 \\
\hline Roger Federer & Tenis & @ rogerfederer & 12,6 milyon & 1,929 bin & 0 \\
\hline Rafa Nadal & Tenis & @ RafaelNadal & 15,7 milyon & 2,840 bin & 3 \\
\hline Drew Brees & $\begin{array}{c}\text { Amerikan } \\
\text { Futbolu }\end{array}$ & @ drewbrees & 3,2 milyon & 4,085 bin & 30 \\
\hline Aaron Rodgers & $\begin{array}{c}\text { Amerikan } \\
\text { Futbolu }\end{array}$ & @ AaronRodgers12 & 4,4 milyon & 3,035 bin & 3 \\
\hline $\begin{array}{c}\text { DeMarcus } \\
\text { Lawrance }\end{array}$ & Beyzbol & @TankLawrance & 243,4 bin & 1,169 bin & 30 \\
\hline Cole Beasley & Beyzbol & @Bease11 & 456,9 bin & 7,196 bin & 1 \\
\hline Tiger Woods & Golf & @TigerWoods & 6,5 milyon & 1,114 bin & 16 \\
\hline İan Paulter & Golf & @IanJamesPoulter & 2,3 milyon & 23 bin & 32 \\
\hline
\end{tabular}

Cristiano Ronaldo 1-31 Ağustos 2019 tarihleri arasında 82,6 milyon takipçisi olan Cristiano hesabından toplamda 11 tweet atmıştır.

Neymar 1-31 Ağustos 2019 tarihleri arasında 45,5 milyon takipçisi olan neymarjr hesabından toplamda 7 tweet atmıştır.

Lebron James 1-31 Ağustos 2019 tarihleri arasında 45 milyon takipçisi olan KingJames hesabından toplamda 59 tweet atmıştır.

Stephen Curry 1-31 Ağustos 2019 tarihleri arasında 14 milyon takipçisi olan StephenCurry30 hesabından toplamda 7 tweet atmıştır.

Roger Federer 1-31 Ağustos 2019 tarihleri arasında 12,6 milyon takipçisi olan rogerfederer hesabından hiç tweet atmamıştır.

Rafa Nadal 1-31 Ağustos 2019 tarihleri arasında 15,7 milyon takipçisi olan RafaelNadal hesabından toplamda 3 tweet atmıştır

Drew Brees 1-31 Ağustos 2019 tarihleri arasında 3,2 milyon takipçisi olan drewbrees hesabından toplamda 30 tweet atmıştır

Aaron Rodgers 1-31 Ağustos 2019 tarihleri arasında 4,4 milyon takipçisi olan AaronRodgers12 hesabından toplamda 3 tweet atmıştır.

DeMarcus Lawrance 1-31Ağustos 2019 tarihleri arasında 243,4 bin takipçisi olan TankLawrance hesabından toplamda 30 tweet atmıştır.

Cole Beasley 1-31 Ağustos 2019 tarihleri arasında 456,9 bin takipçisi olan Bease11 hesabından toplamda 1 tweet atmıştır.

Tiger Woods 1-31 Ağustos 2019 tarihleri arasında 6,5 milyon takipçisi olan TigerWoods hesabından toplamda 16 tweet atmıştır.

Ian Poulter 1-31 Ağustos 2019 tarihleri arasında 2,3 milyon takipçisi olan IanJamesPulter hesabından toplamda 32 tweet atmıştır. 
Tablo 5. Sporcuların Alt boyutlara göre tweet atma sayıları (Ağustos, 2019).

\begin{tabular}{|c|c|c|c|c|c|c|c|}
\hline Sporcu & $\begin{array}{l}\text { Kişisel } \\
\text { Hayatı }\end{array}$ & $\begin{array}{c}\text { İş } \\
\text { Hayatı }\end{array}$ & $\begin{array}{l}\text { Kendi } \\
\text { Branşı }\end{array}$ & $\begin{array}{c}\text { Diğer } \\
\text { Branşlar }\end{array}$ & $\begin{array}{c}\text { Taraftarlara } \\
\text { Cevap }\end{array}$ & $\begin{array}{l}\text { Popüler } \\
\text { Kültü̈r }\end{array}$ & $\begin{array}{c}\text { Resim + } \\
\text { Video }\end{array}$ \\
\hline $\begin{array}{l}\text { Cristiano } \\
\text { Ronaldo }\end{array}$ & 3 & 2 & 7 & 0 & 0 & 0 & 11 \\
\hline Neymar & 5 & 2 & 2 & 0 & 0 & 1 & 7 \\
\hline Lebron James & 31 & 4 & 4 & 4 & 12 & 15 & 33 \\
\hline $\begin{array}{c}\text { Stephen } \\
\text { Curry }\end{array}$ & 3 & 1 & 2 & 1 & 1 & 0 & 6 \\
\hline Roger Federer & \multicolumn{7}{|c|}{ TWEET YOK } \\
\hline Rafael Nadal & 2 & 0 & 2 & 0 & 0 & 0 & 2 \\
\hline Drew Brees & 1 & 0 & 30 & 0 & 1 & 0 & 28 \\
\hline $\begin{array}{c}\text { Aaron } \\
\text { Rodgers }\end{array}$ & 1 & 0 & 1 & 0 & 1 & 0 & 2 \\
\hline $\begin{array}{l}\text { DeMarcus } \\
\text { Lawrance }\end{array}$ & 5 & 3 & 11 & 1 & 11 & 0 & 14 \\
\hline Cole Beasley & 0 & 0 & 1 & 0 & 0 & 0 & 1 \\
\hline Tiger Woods & 4 & 1 & 11 & 0 & 1 & 0 & 13 \\
\hline Ian Paulter & 8 & 1 & 10 & 1 & 10 & 0 & 21 \\
\hline
\end{tabular}

Cristiano Ronaldo 21 tweetinin 3'ünü kişisel hayatıyla ilgili, 2'sini iş hayatıyla ilgili, 7'sini kendi branşıyla ilgili, $11^{\prime}$ ini resim/video olarak twitlemiştir.

Neymar 7 tweetinin 4'ünü kişisel hayatıyla, 2'sini iş hayatıyla, 2'sini kendi branşıyla, 1'ini popüler kültürle, 7'sini resim/video olarak twitlemiştir.

Lebron James 59 tweetinin 31 'ini kişisel hayatıyla ilgili, 4'ünü iş hayatıyla ilgili, 4'ünü kendi branşıyla ilgili, 4'ünü diğer branşlarla ilgili, 10'unu taraftarara cevap olarak, 15'ini popüler kültürle ilgili, 33'ünü resim/video olarak twitlemiştir.

Stephen Curry 7 tweetinin 3'ünü kişisel hayatıyla ilgili, 1'ini kişisel hayatıyla ilgili, 2'sini kendi branşıyla ilgili, 1'ini diğer branşlarla ilgili, 1'ini taraftarlara cevap olarak, 6'sını resim/video olarak twitlemiştir.

Roger Federer 1-31 Ağustos 2019 tarihleri arasında 12,6 milyon takipçisi olan rogerfederer hesabından hiç tweet atmamıştır.

Rafael Nadal 3 tweetinin 2'sini kişisel hayatıyla ilgili, 2'sini kendi branşıla ilgili, 2'sini resim/video olarak twitlemiştir.

Drew Brees 30 tweetinin 1 'ini kişisel hayatıyla ilgili, 30'unu kendi branşıyla ilgili, 1'ini taraftarlara cevap olarak, 27'sini resim/video olarak twitlemiştir.

Aaron Rodgers 3 tweetinin 1'ini kişisel hayatıyla ilgili, 1'ini diğer branşlarla ilgili, 1'ini taraftarlara cevap olarak, 2'sini resim/video olarak twitlemiştir.

DeMarcus Lawrance 30 tweetinin 4'ünü kişisel hayatıyla ilgili, 3'ünü iş hayatıyla ilgili, 11'ini kendi branşıyla ilgili, 1'ini diğer branşlarla ilgili, 11 'ini taraftarlara cevap olarak, 14'ünü resim/video olarak twitlemiştir.

Cole Beasley 1 tweetini kendi branşı ve resim/video olarak twitlemiştir.

Tiger Woods 16 tweetinin 3'ünü kişisel hayatıyla ilgili, 1'ini iş hayatıyla ilgili, 11'ini kendi branşıyla ilgili, 1 'ini taraftarlarar cevap olarak, 13’ünü resim/video olarak twitlemiştir. 
Ian Poulter 32 tweetinin 8'ini kişisel hayatıyla ilgili, 1'ini iş hayatıyla ilgili, 10'unu kendi branşıyla ilgili, 1'ini diğer branşlarla ilgili, 10'unu taraftarlara cevap olarak, 21'ini resim/video olarak twitlemiştir.

Tablo 6. Sporcuların branşlara göre tweetlerinin yüzdelik dağılımı (Ağustos, 2019).

\begin{tabular}{|c|c|c|c|c|c|c|c|c|c|c|c|c|c|c|c|}
\hline & & \multicolumn{2}{|c|}{$\begin{array}{l}\text { Kişisel } \\
\text { Hayatı }\end{array}$} & \multicolumn{2}{|c|}{ İş Hayatı } & \multicolumn{2}{|c|}{$\begin{array}{l}\text { Kendi } \\
\text { Branşı }\end{array}$} & \multicolumn{2}{|c|}{$\begin{array}{l}\text { Diğer } \\
\text { Branşlar }\end{array}$} & \multicolumn{2}{|c|}{$\begin{array}{c}\text { Taraftarlara } \\
\text { Cevap }\end{array}$} & \multicolumn{2}{|c|}{$\begin{array}{l}\text { Popüler } \\
\text { Cevap }\end{array}$} & \multicolumn{2}{|c|}{$\begin{array}{l}\text { Resim+ } \\
\text { Video }\end{array}$} \\
\hline & $\begin{array}{l}\text { Total } \\
\text { Tweet }\end{array}$ & $N$ & $\%$ & $N$ & $\%$ & $N$ & $\%$ & $N$ & $\%$ & $N$ & $\%$ & $N$ & $\%$ & $N$ & $\%$ \\
\hline Futbol & 40 & 8 & 20 & 4 & 10 & 9 & 22,5 & 0 & 0 & 0 & 0 & 1 & 2,5 & 18 & 45 \\
\hline Basketbol & 117 & 34 & 29,05 & 5 & 4,27 & 6 & 5,12 & 5 & 4,27 & 13 & 11,11 & 15 & 12,82 & 39 & 33,33 \\
\hline Tenis & 6 & 2 & 33,33 & 0 & 0 & 2 & 33,33 & 0 & 0 & 0 & 0 & 0 & 0 & 2 & 33,33 \\
\hline $\begin{array}{l}\text { Amerikan } \\
\text { Futbolu }\end{array}$ & 65 & 2 & 3,07 & 0 & 0 & 31 & 47,69 & 0 & 0 & 2 & 3,07 & 0 & 0 & 30 & 46,15 \\
\hline Beyzbol & 47 & 5 & 10,63 & 3 & 6,38 & 12 & 25,53 & 1 & 2,12 & 11 & 23,40 & 0 & 0 & 15 & 31,91 \\
\hline Golf & 81 & 12 & 14,81 & 2 & 2,46 & 21 & 25,92 & 1 & 1,23 & 11 & 13,58 & 0 & 0 & 34 & 41,97 \\
\hline
\end{tabular}

Ağustos 2019'da atılan twitlerin içeriğine bakıldığında; Basketbol branşıyla uğraşan sporcuların Kişisel hayatı ile ilgili atmış olduğu tweet oranı \%33,33 ile zirvede yer alırken, Amerikan futbolcu oyuncularında bu tweet sayısı \%3,07 ile son sırada kendine yer bulmaktadır. İş hayatı ile ilili atılan tweet oranlarına baktığımızda Futbol branşıyla ilgilenen sporcular \%10 ile diğer branşlara göre ilk sırada yer alırken, Tenis ve Amerikan futbolu branşlarında bu oran \%0'dır. Sporcuların Kendi Branşı kategorisinde atmış oldukları tweet sayılarına bakıldığında \%47,69 ile Amerikan futbolu branşı ilk sıradayken, \%5,12 ile Basketbol branşı bu kategoride son sırada yer almaktadır. Diğer branşlar kategorisine bakıldığında en fazla tweet atılan branş \%4,27 ile Basketbol branşı olurken, Futbol, Tenis ve Amerikan futbolu branşlarında hiç tweet atılmamıştır. Taraftarlara Cevap kategorisinde \%23,40 ile Beyzbol branşı liderken, Futbol ve Tenis branşlarında bu kategori altında hiç tweet atılmadığı tabloda gösterilmektedir. Popüler cevap kategorisine bakıldığında \%12,82 ile Basketbol branşı en fazla tweet atılan branş olurken Futbol hariç diğer branşlarda bu kategori altında hiç tweet atılmamıştır. Resim+video kategorisi incelendiğinde \%41,97 ile en fazla Golf branşında tweet atılırken, en az tweet ise Tenis branşında atılmıştır.

\section{Tartışma ve Sonuç}

İnternet dünyasında kullanıcılar bilgilerini ve düşüncülerini kolayca paylaşabildikleri aynı zamanda dünya çapında insanlarla iletişim kurabildikleri bir platform haline dönüşmüşür (Kaşıkçı ve ark., 2014). Günümüzde profesyonel sporcular artık sosyal medyayı kendilerini tanıtmak ve markalaşma için bir araç olarak kullanmaktadır (Kassing ve Sanderson, 2010). Özellikle sponsor markaların tanıtımını sosyal medya aracılığıyla hayranlarına aktarmaktadır. Yıldız sporcuların Ağustos 2018 ve Ağustos 2019 tarihlerinde twitter platformunu aktif kullanma sıklıklarını incelediğimiz çalışma sonuçlarına göre;

Futbol yıldızı Cristiano Ronaldo 2018 Ağustos ayında 21, 2019 Ağustos ayında ise 11 tweet atmıştır. 12 aylık süre boyunca takipçi sayısı 8 milyon artmıştır. Yıldız futbolcu, 2018 Ağustos ayında 11 tweet ile en çok "Kişisel Hayatı" ile ilgili tweet atarken, 2019 Ağustos ayında ise 7 tweet ile en çok "Kendi

25 | P a g e

www.iiste.org 
Branşı" ile ilgili tweet attığı görülmektedir. Diğer bir futbol yıldızı Neymar 2018 Ağustos ayında 29, 2019 Ağustos ayında ise 7 tweet atmıştır. 12 aylık süre boyunca takipçi sayısı 4,5 milyon artmıştır. Brezilyalı yıldız, 2018 Ağustos ayında 13 tweet ile en çok "Kişisel Hayatı" ile ilgili tweet atarken, 2019 Ağustos ayında da sayı düşmesine rağmen 5 tweet ile yine "Kişisel Hayatı ile ilgili tweet attığ görülmektedir.

Futbol branşında yer alan yıldız sporcuların yıllara göre tweet atma sayılarında azalma olmasına rağmen takipçi sayılarında gözle görülür bir artış söz konusudur. Futbolun diğer branşlara göre daha popüler olması, futbol oynayan oyuncularında sosyal medya kazançlarının artmasını sağlamaktadır. Özellikle dünya yıldızı diye adlandırılan Cristiano Ronaldo'nun 2020 Haziran ayında kazancı 1 milyar doları geçen tek futbolcu olma özelliğini taşımaktadır. Yaptığı paylaşımlarla kazancını daha da arttıran yıldız futbolcu sosyal medya paylaşımlarından 52 milyon dolar kazanç sağlamaktadır. Berk ve Bayrak (2019) tarafından yapılan "Yıldız Sporcuların Sosyal Medya Etkileşimi”" adlı çalışma sonuçları da çalışmamızla benzerlik göstermektedir. Ronaldo yapmış olduğu marka paylaşımlarıyla sosyal medyadaki gelirini arttırmaya başlamış, neredeyse futboldan daha fazla kazanmaya başlamıştır. Bir diğer yıldız futbolcu Neymar da sosyal medya kazancıyla gündemde olan futbolculardan biridir. Reklam başına atmış olduğu reklam tweetlerinden yaklaşık 500 bin euro alan yıldız futbolcu sosyal medya tanıtım kazancının ise ortalama 35 milyon euro olduğu belirtilmektedir. Futbolcuların neredeyse maaşlarına yakın bir ücreti sosyal medyadaki paylaşımlarından kazanması sosyal medyanın günümüzde ekonomik olarak ne derece etkili olduğunu bizlere göstermektedir. Yine Berk ve Bayrak (2019) tarafından yapılan çalışmada da Neymar'ın günlük paylaşımlarının daha çok markalarına ait olduğunu ve özellikle taraftarların retweet yaparak aralarında iletişimin kuvvetli olduğu söylenebilir.

Basketbol yıldızı Lebron James 2018 Ağustos ayında 39, 2019 Ağustos ayında ise 59 tweet atmıştır. 12 aylık süre boyunca takipçi sayısı 3,5 milyon artımıştır. Yıldız basketbolcu, 2018 Ağustos ayında 22 tweet ile en çok "Kişisel Hayatı" ile ilgili tweet atarken, 2019 Ağustos ayında ise yine 31 tweet ile "Kişisel Hayatı" ile ilgili tweet attığı görülmektedir. Diğer bir basketbol yıldızı Stephen Curry 2018 Ağustos ayında 15 tweet atarken, 2019 Ağustos ayında ise 7 twet atmıştır. 12 aylık süre boyunca takipçi sayısı 1,2 milyon artmıştır. Amerikalı yıldız, 2018 Ağustos ayında 9 tweet ile en çok "Kişisel Hayatı" ile ilgili tweet atarken, 2019 Ağustos ayında bu sayı düşmesine rağmen 3 tweet ile en çok yine "Kişisel Hayatı "ile ilgili tweet attığı görülmektedir.

NBA'de oynayan basketbol yıldızlarının tweet atma sayllarında azalma NBA yetkilileri tarafindan beklenen bir gelişme olarak görülmektedir. 2017 yılında yapılan araştırmaya göre gece tweet atan oyuncular ertesi gün maçta bir sayı az atıyor ve aynı zamanda şut yüzdeleri düşüyor. Özellike Lebron James play-off zamanı sosyal medya hesaplarını kapatmakta, turnuva boyunca kullanmamaktadır ( Eurohoops, 2018). Genel olarak NBA'in sosyal medyaya bakışını göz önünde tuttuğumuzda yıldız basketbolcuların tweet atmamalarl olağan bir durum olarak görülmektedir. Ancak tweet atan basketbolcuların özellikle sosyal medyadan kazançları öngörülebilir yüksekliktedir. Lebron James'in sponsor içerikli tweetlerinin değeri yaklaşık 140 bin dolar olduğu söylenmektedir (Europort, 2015).

Tenis yıldızı Roger Federer 2018 Ağustos ayında 5, 2019 Ağustos ayında ise hiç tweet atmamıştır. 12 aylık süre boyunca takipçi sayısı 300 bin artmıştır. İsviçreli raket, 2018 Ağustos ayında 3 tweet ile en çok "Kendi Branşı" ile ilgili tweet atarken, 2019 Ağustos ayında ise hiç tweet atmadığı görülmektedir. Diğer bir teniz yıldızı Rafael Nadal 2018 Ağustos ayında 10, 2019 Ağustos ayında ise 3 tweet atmıştır. 12 aylık süre boyunca takipçi sayısı 100 bin artmıştır. İspanyol raket, 2018 Ağustos ayında 4 tweet ile en çok “ Kendi Branşı” ile ilgili tweet atarken, 2019 Ağustos ayında ise hiç tweet atmadığ görülmektedir.

Tenis branşına özgü incelediğimiz Federer ve Nadal'ın attıkları tweet sayılarına bakıldı̆̆ında takipçi sayılarındaki yükselmeye rağmen çok az tweet atılmış, hatta bazı dönemde hiç atılmamıştır. Oyuncuların Twitter hesaplarının yanında Instagram hesaplarında da aktif olduğunu söyleyebiliriz. Instagramın son dönemde güncellenen özelliğiyle canlı yayın devreye girmiş tenis maçları bu platform üzerinden canlı yayınlanmaya başlamıştır. Hatta 2020 Nisan ayında Nadal ve Federer ortak canlı yayın görüşmesi yapmış, görüşme rekor kırarak 58,4 milyon izlenme sayısına ulaşmıştır. Instagramın en azından tenis sporcu için Twitter platformuna göre daha fazla kullanıcısı olmasl, sporcuların da bu kadar az saylda tweet atma nedenleri arasında olduğu söylenebilir. Akkaya ve Zerenler (2017)'in yapmış oldukları "Sosyal Medya Ve Spor Pazarlamasi İlişkisi Taraftar Tutumlarini Belirlemeye

26 | P a g e

www.iiste.org 
Yönelik Bir Araştirma: Beşiktaş Spor Kulübü Örneği” adlı çalışmada taraftarların sosyal medya aracılı̆̆ıla taraftarı oldukları oyuncu veya takımlar arasında bilgi sahibi olmak, maç bilgisi, oyuncularla iletişime geçebilme amacını taşılıkları görülmüştür.

Amerikan futbolu yıldızı Drew Brees 2018 Ağustos ayında 20, 2019 Ağustos ayında ise 30 tweet atmıştır. 12 aylık süre boyunca takipçi sayısı 100 bin artmıştır. Amerikalı yıldız, 2018 Ağustos ayında 8 tweet ile en çok "Kişisel Hayatı" ile ilgili tweet atarken, 2019 Ağustos ayında ise 30 tweet ile en çok "Kendi Branşı" ile iligili tweet attı̆̆ı görülmektedir. Diğer bir amerikan futbolu yıldızı Aaron Rodgers 2018 Ağustos ayında 13, 2019 Ağustos ayında ise 3 tweet atmıştır. 12 aylık süre boyunca takipçi sayısı 20 bin azalmıştır. Amerikalı yıldız, 2018 Ağustos ayında 6 tweet ile en çok "Kişisel Hayatı" ile ilgili tweet atarken, 2019 Ağustos ayında bu sayı düşerek 1 tweet ile en çok "Kişisel Hayatı”, "Kendi Branşı" ve "Taraftarlara Cevap" şeklinde attığı görülmektedir.

Amerikan futbolu branşına özgü incelediğimiz sporcularının twitter hesaplarını incelediğimiz diğger branşlara göre takipçi sayılarında artma hızının az sayıda olduğunu söyleyebiliriz. Daha çok sporcuların kişisel hayatlarıyla ilgili tweet attı̆̆ını görmekteyiz. Sporcuların twitter aracını aktif kulllanmamalarına rağmen 2018 yllında SuperBowl etiketiyle twitterdan yayınlanan şampiyonluk maçı görüntüleri ve sonrasında gösterilen kutlamalar 8,2 milyon kez paylaşılmıştır (Ajansspor, 2018). 52.Super Bowl karşılaşması sporcular için bir dönüm noktası olacă̆l, spor kulüplerinin sosyal medyanın gücünü ilerleyen zamanlarda daha aktif olarak kullanabileceğini söyleyebiliriz.

Beyzbol yıldızı DeMarcus Lawrance 2018 Ağustos ayında 9, 2019 Ağustos ayında ise 30 tweet atmıştır. 12 aylık süre boyunca takipçi sayısı 117,4 bin artmıştır. Amerikalı yıldız, 2018 Ağustos ayında 6 tweet ile en çok "Kendi Branşı" ile ilgili tweet atarken, 2019 Ağustos ayında ise 11 tweet ile en çok "Kendi Branşı" ve "Taraftarlara Cevap" şeklinde arttığı görülmektedir. Diğer bir beyzbol yıldızı Cole Beasley 2018 Ağustos ayında 26, 2019 Ağustos ayında ise 1 tweet atmıştır. 12 aylık süre boyunca takipçi sayısı 23,2 bin artmıştır. Amerikalı yıldız, 2018 Ağustos ayında 6 tweet ile en çok "Kendi Branşı" ile ilgili tweet atarken, 2019 Ağustos ayında ise sadece 1 tweeti "Kendi Branşı" ile attığ1 görülmektedir.

Beyzbol branşında yer alan sporcuların tweet atma sayıları incelendiğinde, iki sporcu arasında farklılık olduğu görülmektedir. Lawrance'ın tweet saylsı artarken, Beasley'de ise düşüş göze çarpmaktadır. Twitter'da kullanıma bağlı taraftarların gösterdiği ilginin kısa vadede başarılı fakat uzun vadede etkisi olmadĭ̆ yapılan çalışmalarda gösterilmektedir. Watanabe ve ark (2015) tarafindan yapılan 40'dan fazla yapılan çalışmada incelenen sporcuların twitter kullanımlar bir yıldı etkisi yaratmadiklarl, sporcuların kendilerini reklam ve sponsorluk anlaşmalarlyla pazarlamalarının ekonomik olarak daha fazla katkı sağlayacaklarını belirtmişlerdir. Şenduran ve ark. (2018) tarafindan yapılan Sportif Illetişimde Facebook ve Twitter adlı çalışmada sosyal medyanın sık kullanılmasının sporcuların kaygı seviyelerinin artışına sebep olduğunu belirtmişlerdir. Bu bağlamda, sporcuların sosyal medyayı pazarlama aracı olarak kullanmalarının daha fazla katkı să̆layabileceğini söyleyebiliriz.

Golf yıldızı Tiger Woods 2018 Ağustos ayında 24, 2019 Ağustos ayında ise 16 tweet atmıştır. 12 aylık süre boyunca takipçi sayısı 190 bin artmıştır. Amerikalı yıldız, 2018 Ağustos ayında 21 tweet ile en çok "Kendi Branşı" ile ilgili tweet atarken, 2019 Ağustos ayında ise bu sayı düşerek 11 tweet ile yine "Kendi Branşı" ile ilgili tweet attğı görülmektedir. Diğer bir golf yıldızı Ian Paulter 2018 Ağustos ayında 17, 2019 Ağustos ayında ise 32 tweet atmıştır. 12 aylık süre boyunca takipçi sayısı 100 bin azalmıştır. Birleşik Krallık yıldızı, 2018 Ağustos ayında 13 tweet ile en çok "Kendi Branşı" ile ilgili tweet atarken, 2019 Ağustos ayında ise en çok 10 tweet ile "Kendi Branşı" ve "Taraftarlara Cevap" şeklinde attığ 1 görülmektedir.

Golf branşına ait sporcuları incelediğimizde Tiger Woods'un ön plana çıktı̆̆ını görmekteyiz. 2013 yılında 78, 1 milyon dolarla dünyanın fazla kazanan sporcu unvanını almıştır. 2019 yılında sponsoru olduğu Nike ile ilk kez kameralar karşısına geçen Woods reklamlarda yer almaya başlamış, paylaşımlarıyla da sosyal medyada aktif kullancı olmuştur. Paulter ise kendi braşıly ilgili tweet sayısı kadar taraftarlara cevap vererek hayranlarlyla iletişimde olmuş, sosyal medyayı hayran kitlesiyle iletişime geçmek için kullandiğını söyleyebiliriz. Atalı ve Karacan (2013) tarafindan yapılan "Üniversite Liglerine Katılan Sporcuların Bilgi Teknolojileri ve Sosyal Medya Araçları Kullanımı"

27 | P a g e

www.iiste.org 
adlı çalışmada sporcuları bağlı bulunduğu branşa özgü organizasyona yönelik ve müsabakalarlyla ilgili bilgi paylaşımında bulunduklarını belirtmişstlerdir.

\section{Kaynaklar}

Akkaya, Ö. ve Zerenler, M. (2017). Sosyal Medya Ve Spor Pazarlamasi İlişkisi Taraftar Tutumlarini Belirlemeye Yönelik Bir Araştirma: Beşiktaş Spor Kulübü Örneği, Süleyman Demirel Üniversitesi İktisadi ve İdari Bilimler Fakültesi Dergisi Y.2017, C.22, S.4, s.945-963.

Ashley C. And Tuten T.(2015). Creative Strategies in Social Media Marketing: An Exploratory Study of Branded Social Content and Consumer Engagement, Psychology and Marketing, Vol. 32(1): 15-27 (January 2015)

Atatl, L. ve Karacan, Ç. (2013). Üniversite Liglerine Katılan Sporcuların BilgiTeknolojileri ve Sosyal Medya Araçları Kullanımı, Çankırı Karatekin Üniversitesi Sosyal Bilimler Enstitüsü Dergisi 4(2): 217-226

Berk, O. ve Bayrak, T. (2019). Yıldız Sporcuların Sosyal Medya Etkileşimi, e-Journal of New Media / Yeni Medya Elektronik Dergi - eJNM ISSN: 2548-0200, September 2019 Volume 3 Issue 3, p.226-236

Frederick E. (2017). Malice in the Digital Palace: A Commentary on Athletes, Social Media, and Defamation, Journal of Legal Aspects of Sport, 2017, 27, $79 \quad-89$ https://doi.org/10.1123/jlas.2016-0017

Gantz W, Lewis N. (2014). Sports on Traditonal and Newer Digital Media: Is There Really a Fight for Fans? Television \& New Media, 15 (8): 760-768.

https://ajansspor.com/haber/52-super-bowl-macina-sosyal-medyada-buyuk-ilgi-216396 (Erişim tarihi: 17.05.2020)

https://www.eurohoops.net/tr/trademarks-tr/757395/1nbain-yeni-derdi-sosyal-medya-bagimliligi/ (Erişim tarihi: 21.05.2020)

https://www.eurosport.com.tr/basketbol/nba/2014-2015/lebron-james-in-bir-tweeti-140-bindolar_sto4872202/story.shtml (Erișim tarihi: 04.06.2020)

http://www.milliyet.com.tr/altinordu-baskani-ozkan-dan-sosyal---2732128-skorerhaber (Erişim tarihi: 05.01.2020).

https://www.gzt.com/spor/galatasaraya-sosyal-medya-cezasi-100-bin-tl-3147959) (Erişim tarihi: 05.01 .2020

https://www.bbc.co.uk/newsround/49409859) (Erişim tarihi: 16.02.2020)

Kaşıkcı, D., Çağıltay, K., Karakuş, T., Kurşun, E., \& Oğan, C. (2014). Türkiye ve Avrupa'daki çocukların internet alışkanlıkları ve güvenli internet kullanımı. Eğitim ve Bilim, 39(171): 230243.

Kassing, J. W., \& Sanderson, J. (2010). Fan-athlete interaction and Twitter tweeting through the Giro: A case study. International Journal of Sport Communication, 3(1), 113-128.

Lebel K, Danylchuk K. (2012). How tweet it is: A gendered analysis of Professional tennis players' self-presentation on Twitter. International Journal of Sport Communication, 5, 461-480.

28 | P a g e

www.iiste.org 
Lee J. (2015). Reaching Out of the World. IAAF New Studies in Athletics. 30 (2): 7-15.

Murdough C.(2009). Social Media Measurement: It's Not Impossible, Journal of Interactive Advertising Volume 10. 94-99

Pegoraro A. (2014). Twitter as Disruptive Innovation in Sport Communication, Communication \& Sport, 2014, Vol. 2(2) 132-137

Şenduran, F., Korkmaz, N. H., Kasap M., Acar, Z. A., Yalniz, U., Kaçar, M. (2018). Facebook ve Twitter'ın Spor Alanına Etkileri [ Facebook and Twitter Effects on Sports Space], Spor Eğitim Dergisi, 2 (2), 12-28.

Shepherd IDF. (2005) From Cattle and Coke to Charlie: Meeting the Challenge of Self Marketing and Personal Branding, Journal of Marketing Management, 21:5-6, 589-606, DOI: $10.1362 / 0267257054307381$

Vural Z.B.A. ve Bat M. (2010). Yeni Bir İletişim Ortamı Olarak Sosyal Medya: Ege Üniversitesi İletişim Fakültesine Yönelik Bir Araştırma, Journal of Yasar University 2010 20(5) 3348-3382 